\title{
Evaluation of Thyroid Function Status in Polycystic Ovary Syndrome
}

\author{
Dr. Syeda Sobia Harmain ${ }^{1}$, Dr. Mohd Inayatulla Khan ${ }^{2}$ \\ ${ }^{1}$ PG, Department of Physiology, Kakatiya Medical College and MGM Hospital, Warangal, Telangana State. \\ ${ }^{2}$ Assistant Professor, Department of Physiology, Rajiv Gandhi Institute of Medical Sciences [RIMS], Adilabad, Telangana State.
}

Address for communication: Dr. Mohd Inayatulla Khan, Department of Physiology, Rajiv Gandhi Institute of Medical Sciences, Adilabad-504001, Telangana State, India.

Email: drkhan123@rediffmail.com

\section{ABSTRACT}

Background: PCOS is very commonly seen in young females with chronic anovulatory cycles. It is manifested by features of hyperandrogenism, polycystic ovaries. The risk of insulin resistance is greater in patients with PCOS. There is also a greater incidence of type 2 diabetes, obesity and cardiovascular diseases in patients with PCOS. There are associated endocrinal abnormalities with PCOS most common of which include hypothyroidism. Therefore we in the present study tried to evaluate the existence of hypothyroidism in patients with PCOS in the patients reporting to our Hospital.

Methods: The present study was conducted in the Department of Obstetrics and gynecology, MGM Hospital and Kakatiya Medical College, Warangal. Institutional Ethical committee permission was obtained for the study. The duration of the study was from January 2018 to May 2019. N=30 patients were detected with PCOS during the study period. A similar number of age-matched controls without PCOS were taken for comparison. Anthropometric measurements were made for $\mathrm{BMI}$, waist-hip ratio calculation. $\mathrm{TSH}, \mathrm{FSH}, \mathrm{LH}$, and Testosterone were estimated by Chemiluminescence ImmunoAssay (CLIA) technique.

Results: The Mean Bodyweight $62.17 \mathrm{Vs} 49.33 \mathrm{Kgs}$, The mean BMI was $24.03 \mathrm{Vs} 22.48 \mathrm{Kg} / \mathrm{m} 2$. The mean TSH values were $5.33 \mathrm{Vs} 2.51 \mu \mathrm{lU} / \mathrm{ml}$. The mean FSH values were $12.27 \mathrm{Vs} 8.49$ $\mu \mathrm{lU} / \mathrm{ml}$ the mean LH was $4.27 \mathrm{Vs} 10.49 \mu \mathrm{lU} / \mathrm{ml}$ and the mean Testosterone levels were $69.73 \mathrm{Vs} 9.28 \mathrm{ng} / \mathrm{ml}$.

Conclusion: The present study concludes that patients with PCOS have a greater frequency of thyroid dysfunctions including other endocrinal abnormalities. Accordingly, those diagnosed with PCOS must undergo complete endocrinal investigations. This can help to identify the co-existing endocrinal abnormalities and treatment is given accordingly to prevent morbidity and mortality.

Keywords: Polycystic Ovary Syndrome, Thyroid functions INTRODUCTION

Polycystic ovary syndrome [PCOS] is a common chronic anovulatory disorder usually associated with androgen excess.
It occurs in approximately $5-10 \%$ of reproductive women ${ }^{[1]}$. The reported prevalence of hypothyroidism in Indian adults is approximately $10 \%$. The etiology of PCOS is considered multifactorial. It is also found to be associated with increased metabolic and cardiovascular risk factors. These risks are associated with insulin resistance which is exaggerated by obesity. However, insulin resistance may also found to be present in non-obese women with PCOS. Thyroid disorders and PCOS are two different endocrinal disorders but have many features that are common in both. An increase in ovarian volume and cystic changes has been seen in primary hypothyroidism. There is also an increased presence of thyroid disorders in women with PCOS as compared to the normal population ${ }^{[1-4]}$. Women in reproductive age with PCOS have symptoms associated with reproductive morbidity including infertility, irregular uterine bleeding, and pregnancy loss. In the early stages of the thyroid, dysfunctions change in ovulation and endometrial receptivity is seen which affects fertility ${ }^{[5]}$. In the past, some studies have been conducted across the world regarding thyroid disorders in PCOS patients. They have shown that higher levels of TSH are associated with a four-time higher prevalence of autoimmune thyroiditis in PCOS subjects ${ }^{[6]}$. The pathophysiology linking hypothyroidism with PCOS is a rise in thyrotropin-releasing hormone TSH leads to increased prolactin and TSH release. Prolactin contributes towards polycystic ovarian morphology by inhibiting ovulation due to changes in the ratio of FSH and $\mathrm{LH}$ and increased DHEA from adrenal glands [7]. The increase in TSH also causes increased collagen deposition in ovaries. It is therefore said that the severity of ovarian morphology also depends on the duration and severity of hypothyroidism. Van Wyk and Grumbach syndrome show that long-standing untreated cases of congenital hypothyroidism lead to change in ovarian morphology so much that it may sometimes be mistaken for ovarian malignancy ${ }^{[8]}$. Certain common factors that predispose the individual to both the disorders have not been established in this group of population. Hence we in the present study tried to explore the connection between the two disorders. 


\section{Material and methods}

This cross-sectional prospective study was conducted in the Department of Obstetrics and gynecology, MGM Hospital and Kakatiya Medical College. Institutional Ethical committee permission was obtained for the study. Written consent was obtained from all the participants of the study after explaining the nature of the study in the local language. The duration of the study was from January 2018 to May 2019. Inclusion criteria: all the women of reproductive age diagnosed with PCOS on USG. Women with complain of infertility, menstrual irregularities, and miscarriages. Exclusion criteria: patients not fitting in the inclusion criteria, Patients with other endocrinal abnormalities, patients not willing to participate in the study voluntarily. Based on the inclusion and exclusion criteria a total $\mathrm{n}=30$ patients were identified during the study period. A similar number of $n=30$ females were included to act as controls. A detailed medical history, history of past illnesses, family history and complete menstrual history including menstrual irregularities, infertility, history of last pregnancy, lactation, any miscarriages were recorded for each patient. The patient was clinically examined for signs and symptoms of hirsutism, acne, alopecia, deepening of voice were noted. Anthropometric measurements were done as per standard protocol which included height, weight, waist circumference; hip circumference and BMI and waist-hip ratio were calculated. The diagnosis of PCOS was based on Rotterdam criteria ${ }^{[9,10]}$. The patients were subjected to laboratory investigations. An 8 -10 hours fasting blood sample of $5 \mathrm{ml}$ was obtained from the antecubital vein with aseptic precaution in a Vacutainer. The serum was separated for estimation. FBS, TSH, Total testosterone was measured. Glucose was analyzed by a fully automatic chemistry analyzer using the GOD-POD method. The serum TSH, FSH, and Total testosterone were analyzed in Seimens Advia Centura XP with chemiluminescence immunoassay technique. Normal levels of TSH were 3.5-5 $\mu \mathrm{IU} /$ $\mathrm{ml}$ and values $>5 \mu \mathrm{lU} / \mathrm{ml}$ as the hypothyroid state. Normal values of FSH were 4.5 to $21.5 \mu \mathrm{IU} / \mathrm{ml}$ and Normal serum total testosterone as $14-76 \mathrm{ng} / \mathrm{ml}$ and $>76 \mathrm{ng} / \mathrm{ml}$ as a hyperandrogenic state.

\section{Results}

A total of $n=30$ patients were detected during the study period having PCOS and age-matched controls were taken from the normal population with no PCOS by USG or hypothyroidism on laboratory investigations. The data was analyzed between the two groups. The table 1 shows that the most common age groups of patients in the study group were from $26-30$ years $46.67 \%$ followed by $31-35$ years $43.33 \%$. In the control group $21-25$ years and $26-30$ years were $43.33 \%$ and $13.33 \%$ were from $31-35$ years age group.

Table 1: the age-wise and group-wise distribution of the cases in the study

\begin{tabular}{|l|c|c|c|c|}
\hline \multirow{2}{*}{$\begin{array}{c}\text { Age } \\
\text { group }\end{array}$} & \multicolumn{2}{|c|}{ Study group } & \multicolumn{2}{c|}{ Control group } \\
\cline { 2 - 5 } & Number (n) & Percentage & Number (n) & Percentage \\
\hline $\mathbf{2 1 - 2 5}$ & 02 & 6.67 & 13 & 43.33 \\
\hline $\mathbf{2 6 - 3 0}$ & 14 & 46.67 & 13 & 43.33 \\
\hline $\mathbf{3 1 - 3 5}$ & 13 & 43.33 & 04 & 13.33 \\
\hline $\mathbf{3 6 - 4 0}$ & 01 & 3.33 & 00 & 00.00 \\
\hline Total & 30 & 100 & 30 & 100 \\
\hline
\end{tabular}

Measurement of weight and comparison between the two groups revealed the mean weight in the study group was 62.17 \pm 4.37 which was higher than the mean values from the control group. The calculated $p$ values by the chi-square test were < 0.0001 which is considered highly significant. It indicates the women in the study were significantly overweight as compared to the normal control group shown in table 2 .

Table 2: Comparison of mean weight between the groups

\begin{tabular}{|c|c|c|c|c|c|}
\hline $\begin{array}{c}\text { Weight } \\
\text { in Kgs }\end{array}$ & $\begin{array}{c}\text { Number of } \\
\text { cases (N) }\end{array}$ & Mean \pm SD & df & t Stat & P values \\
\hline Study group & 30 & $62.17 \pm 4.37$ & & & \\
\hline Control group & 30 & $49.33 \pm 6.45$ & 58 & 9.020695 & $<0.0001 *$ \\
\hline
\end{tabular}

The determination of $\mathrm{BMI}$ in $\mathrm{Kg} / \mathrm{m} 2$ was done for each case based on the measurements of weight and height according to the standard format. The mean values of BMI were $24.03 \pm$ 1.26 higher in the study group as compared to the control group $22.48 \pm 3.48$. The $p$ values were $<0.02$ which were considered as significant given in table 3 .

Table 3: Comparison of mean BMI Kg/m2 between the groups

\begin{tabular}{|c|c|c|c|c|c|}
\hline $\begin{array}{c}\text { BMI in } \\
\mathbf{k g} / \mathbf{m} 2\end{array}$ & $\begin{array}{c}\text { Number of } \\
\text { cases (N) }\end{array}$ & Mean \pm SD & df & t Stat & P values \\
\hline Study group & 30 & $24.03 \pm 1.26$ & & & \\
\hline Control group & 30 & $22.48 \pm 3.48$ & 58 & 2.2804 & $<0.02 *$ \\
\hline
\end{tabular}

* Significant

The mean values of TSH in the study group were $5.33 \pm 1.29$ and in the control, the mean TSH values were $2.51 \pm 0.63 \mu \mathrm{IU} /$ $\mathrm{ml}$ and the $\mathrm{p}$ values were found to be $<0.001$ hence found to be significant table 4 .

Table 4: Comparison of mean between TSH values the groups

\begin{tabular}{|c|c|c|c|c|c|}
\hline $\begin{array}{c}\text { TSH values in } \\
\boldsymbol{\mu l U} / \mathrm{ml}\end{array}$ & $\begin{array}{c}\text { Number of } \\
\text { cases (N) }\end{array}$ & Mean \pm SD & df & t Stat & P values \\
\hline Study group & 30 & $5.33 \pm 1.29$ & & & \\
\hline Control group & 30 & $2.51 \pm 0.63$ & 58 & 10.68 & $<0.001 *$ \\
\hline
\end{tabular}




\section{* Significant}

Chart 1: showing the Mean TSH values between the two groups

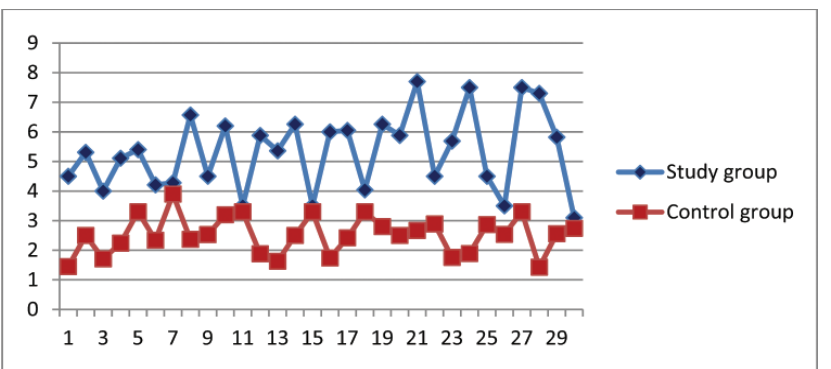

The mean levels of Follicle Stimulating Hormone FSH were measured in both the study and the control group. The mean FSH values were $12.27 \pm 1.90$ in the study group and $5.49 \pm$ $2.05 \mu \mathrm{lU} / \mathrm{ml}$. The $\mathrm{p}$ values were not found to be significant (Table 5). Similarly, the $\mathrm{LH}$ values were recorded and in the study group, the $\mathrm{LH}$ values were $4.27 \pm 0.45$ and the control group the values were $10.49 \pm 2.05$ (table 6). Consequently, the $\mathrm{LH}$ to FSH ratio in the study was approximately 3:1 which is a typical feature in patients of PCOS.

Table 5: Comparison of mean FSH values between the groups

\begin{tabular}{|c|c|c|c|c|c|}
\hline $\begin{array}{c}\text { FSH values in } \\
\boldsymbol{\mu l U} / \mathrm{ml}\end{array}$ & $\begin{array}{c}\text { Number of } \\
\text { cases (N) }\end{array}$ & Mean \pm SD & df & t Stat & P values \\
\hline Study group & 30 & $12.27 \pm 1.90$ & & & \\
\hline Control group & 30 & $8.49 \pm 2.05$ & 58 & 18.0503 & $>0.1$ \\
\hline
\end{tabular}

Table 6: Comparison of mean LH values between the groups

\begin{tabular}{|c|c|c|c|c|c|}
\hline $\begin{array}{c}\text { LH values in } \\
\boldsymbol{\mu l U} \mathbf{l} \mathbf{m l}\end{array}$ & $\begin{array}{c}\text { Number of } \\
\text { cases (N) }\end{array}$ & Mean \pm SD & df & t Stat & P values \\
\hline Study group & 30 & $4.27 \pm 0.45$ & & & \\
\hline Control group & 30 & $10.49 \pm 2.05$ & 58 & 18.0503 & $<0.01^{*}$ \\
\hline
\end{tabular}

* Significant

The mean testosterone levels in the study were $69.73 \pm 9.28$ and the control group was $22.10 \pm 6.72 \mathrm{ng} / \mathrm{ml}$. The women with PCOS are found to have increased both total testosterone and free testosterone levels. This increased testosterone levels in the woman's body suppress the normal menstruation and ovulation.

Table 7: Comparison of mean Testosterone values between the groups

\begin{tabular}{|l|c|c|c|c|c|}
\hline $\begin{array}{c}\text { Testosterone } \\
\mathbf{n g} / \mathbf{m l}\end{array}$ & $\begin{array}{c}\text { Number of } \\
\text { cases (N) }\end{array}$ & Mean \pm SD & df & t Stat & P values \\
\hline Study group & 30 & $69.73 \pm 9.28$ & & & \\
\hline Control group & 30 & $22.10 \pm 6.72$ & 58 & 22.748 & $<0.001 *$ \\
\hline
\end{tabular}

Chart 2: showing the Mean Testosterone values between the two groups

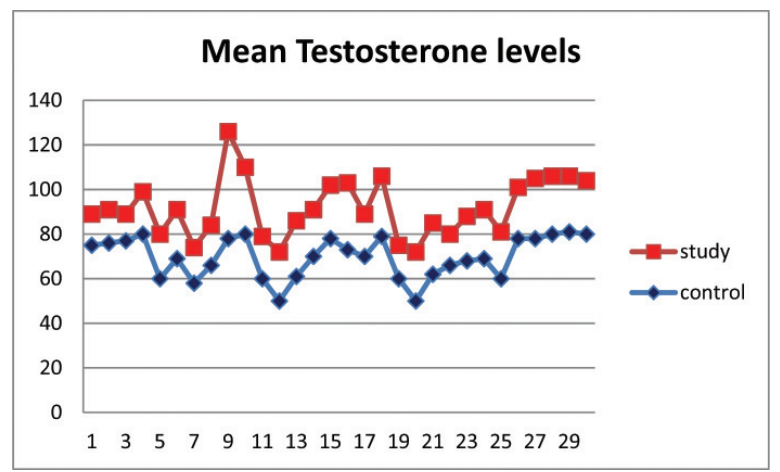

Discussion

In this study, we found out of the total $n=30$ patients of PCOS the commonly involved patients in the age group were 26 - 30 years. A similar study by A Jansirani et al; ${ }^{[11]}$ found $11 \%$ of patients below the age of 19 years and $89 \%$ were aged 20 and above. In this study, we found only $n=2(6.66 \%)$ in the age group of 21 - 25 years. In our study, we found $n=13$ (43.33\%) out of $n=30$ PCOS patients with hypothyroidism. Uma Sinha et al; ${ }^{[5]}$ showed the prevalence of hypothyroidism in $22.7 \%$ of patients with PCOS in eastern India and Maryam et al; [12] and Janssen et al; ${ }^{[13]}$ have shown $26.9 \%$ prevalence of autoimmune thyroiditis in PCOS women. This shows that there is a higher prevalence of hypothyroidism in PCOS women as compared to the general population. Some factors could be responsible for this; the first one is women with PCOS are predisposed at a greater level to autoimmune diseases due to excessive estrogen sections ${ }^{[14]}$. The second is the action of estrogen on functions of B lymphocytes which causes their proliferation. Estrogen receptors have also been found on Tcells and macrophages ${ }^{[15]}$. In this study, we found the mean weight in study group $62.17 \mathrm{Vs} 49.33 \mathrm{Kg}$ and the mean BMI $24.03 \mathrm{Vs} 22.48 \mathrm{~kg} / \mathrm{m}^{2}$. In a study by Moustafa MM et al; ${ }^{[16]}$ the PCOS patients exhibited greater BMI as compared to controls 28.6 vs. $24.9 \mathrm{~kg} / \mathrm{m}^{2}$. Although the BMI was lesser in our group of patients it may be also due to variation in genetic background and geographic locations. The LH levels in the study were $4.27 \mathrm{Vs} 10.49 \mu \mathrm{IU} / \mathrm{ml}$. The mean FSH levels were $12.27 \mathrm{Vs} 8.49 \mu \mathrm{lU} / \mathrm{ml}$. The LH/FSH ratio was greater than $2: 1 \mathrm{in}$ $63.33 \%$ of cases of the present study. Ganvir S et al; ${ }^{[17]}$ in a similar study found the LH/FSH ratio of more than 2 was found in $60 \%$ of the cases, 41 subjects (68\%) were insulin resistant. The patients in the study group were having complains of menstrual irregularities in $n=25$ (83.33\%). Najem et al; ${ }^{[18]}$ in their study have shown menstrual irregularity as the prominent symptom present in $93 \%$ of patients with PCOS. Carmina E Lobo RA et al; ${ }^{[19]}$ have shown $60-85 \%$ of patients with menstrual irregularities in PCOS. In this study, we found the mean testosterone values of $69.73 \mathrm{Vs} 22.10 \mathrm{ng} / \mathrm{ml}$ in the study versus the control population. Hyperandrogenism is one of the key 
features of the PCOS phenotype and it is said to be present in approximately $60 \%$ of females ${ }^{[20]}$. Hence clinical markers of hyperandrogenism like hirsutism, acne, and alopecia are commonly seen in patients with PCOS ${ }^{[21,22]}$. The diagnosis of PCOS according to Rotterdam criteria patients must display two of the three features to be diagnosed as PCOS. The presence of polycystic ovaries by ultrasound is important for the diagnosis of PCOS. However, only the presence of polycystic ovaries cannot guarantee PCOS. The PCO under ultrasound is the presence of 12 or more follicles in ovaries measuring 2$9 \mathrm{~mm}$ in diameter and increased ovarian volume $>10 \mathrm{ml}$ is a must for diagnosis of PCOS ${ }^{[23]}$. As far as treatment is concerned women with PCOS not looking to get pregnant administration of combined OCPs are given as the first line of treatment. The OCPs tends to regulate the menstrual cycle and also decreases the section of adrenal androgens ${ }^{[24]}$. Adopting a healthy lifestyle may not reverse PCOS however; it will control associated conditions such as obesity and cardiovascular diseases. Apart from that those detected with hypothyroidism must be given suitable dose thyroxine for the elevation of hypothyroidism.

\section{Conclusion}

The present study concludes that patients with PCOS have a greater frequency of thyroid dysfunctions including other endocrinal abnormalities. Accordingly, those diagnosed with PCOS must undergo complete endocrinal investigations. This can help to identify the co-existing endocrinal abnormalities and treatment is given accordingly to prevent morbidity and mortality.

\section{REFERENCES}

1. Sinha U, Sinharay K, Saha S, Longkumer TA, Baul SN, Pal SK. Thyroid disorders in polycystic ovarian syndrome subjects: A tertiary hospital-based cross-sectional study from Eastern India. Indian J Endocrinol Metab. 2013; 17:304-09.

2. Benetti-Pinto CL, Berini Piccolo VR, Garmes HM, Teatin Juliato CR. Subclinical hypothyroidism in young women with polycystic ovary syndrome: An analysis of clinical, hormonal, and metabolic parameters. Fertil Steril. 2013; 99:588-92.

3. Ramanand SJ, Ghongane BB, Ramanand JB, Patwardhan $\mathrm{MH}$, Ghanghas RR, Jain SS. Clinical characteristics of polycystic ovary syndrome in Indian women. Indian J Endocrinol Metab. 2013; 17:138-45.

4. Janssen OE, Mehlmauer N, Hahn S, Offner AH, Gärtner R. High prevalence of autoimmune thyroiditis in patients with polycystic ovary syndrome. Eur J Endocrinol. 2004;150:363-69.

5. Uma Sinha, Keshab Sinharay, Sudipta Saha, T. Amenla Longkumer, Shuvra Neel Baul, Salil Kumar Pal.Thyroid disorders in polycystic ovarian syndrome subjects: A tertiary hospital-based cross-sectional study from Eastern India. Indian J Endocrinol Metab. 2013 Mar-Apr; 17(2): 304-09.

6. Janssen OE, Mehlmauer N, Hahn S, Offner AH, Gärtner R. High prevalence of autoimmune thyroiditis in patients with polycystic ovary syndrome. Eur J Endocrinol. 2004;150:363-69.

7. Rajiv Singla, Yashdeep Gupta, Manju Khemani, Sameer Aggarwal. Thyroid disorders and polycystic ovary syndrome: An emerging relationship. Indian J Endocrinol Metab. 2015 Jan-Feb; 19(1): 25-29.

8. Van Wyk JJ, Grumbach MM. Syndrome of precocious menstruation and galactorrhea in juvenile hypothyroidism. An example of hormonal overlap in pituitary feedback. J Pediatr. 1960; 57:416-35.

9. Dewailly D, Hieronimus S, Mirakian P, Hugues JN. Polycystic ovary syndrome (PCOS). Ann Endocrinol. 2010; 71:8-13.

10. Rotterdam ESHRE/ASRM-Sponsored PCOS Consensus Workshop Group. Revised 2003 consensus on diagnostic criteria and long-term health risks related to polycystic ovary syndrome. Hum Reprod 2004;19:41-47.

11. A Jansirani R, Ramadevi K. Evaluation of thyroid function status in newly diagnosed polycystic ovarian syndromeAn analysis in a tertiary care hospital. National Journal of basic medical sciences 2016; 7(2): 88-93.

12. Kachuei M, Jafari F, Kachuei A, Keshteli AH. Prevalence of autoimmune thyroiditis in patients with polycystic ovary syndrome. Arch Gynecol Obstet 2012;285:853-6.

13. Janssen OE, Mehlmauer N, Hahn S, Offner AH, Gärtner R. High prevalence of autoimmune thyroiditis in patients with polycystic ovary syndrome. Eur J Endocrinol 2004; 150:363-69.

14. Fair weather D, Rose NR. Women and autoimmune diseases. Emerg Infect Dis: 2004; 10:2005-11.

15. Cutolo M, Sulli A, Straub RH. Estrogen metabolism and autoimmunity. Autoimmun Rev 2012; 11:A460-64.

16. Moustafa MM, Jamal MY, and Al-Janabi RD. Thyroid hormonal changes among women with the polycystic ovarian syndrome in Baghdad - a case-control study. F1000 Research 2019; 8:669.

17. Ganvir S, Sahasrabuddhe AV, Pitale SU. Thyroid function tests in polycystic ovarian syndrome. Natl J Physiol Pharm Pharmacol 2017;7(3):269-272.

18. Najem F, Elmehdawi R, Swalem A. Clinical and Biochemical Characteristics of Polycystic Ovary Syndrome in BenghaziLibya; A Retrospective Study. Libyan J Med 2008; 3:7174. 
19. Carmina E, Lobo RA. A comparison of the relative efficacy of antiandrogens for the treatment of acne in hyperandrogenic women. Clin Endocrinol. 2002; 57:23134.

20. Balen AH, Conway GS, Kaltsas G, Techatrasak K, Manning PJ, West C, Jacobs HS. Polycystic ovary syndrome: the spectrum of the disorder in 1741 patients. Hum Reprod. 1995; 10:2107-11.

21. DeUgarte CM, Woods KS, Bartolucci AA, Azziz R. Degree of facial and body terminal hair growth in unselected black and white women: toward a populational definition of hirsutism. J Clin Endocrinol Metab. 2006; 91:1345-50.

22. Vermeulen A, Verdonck L, Kaufman JM. A critical evaluation of simple methods for the estimation of free testosterone in serum. J Clin Endocrinol Metab. 1999; 84:3666-72.

23. Balen AH, Laven JS, Tan SL, Dewailly D. Ultrasound assessment of the polycystic ovary: International consensus definitions. Hum Reprod Update. 2003; 9:50514.

24. Erin K. Barthelmess, Rajesh K. Naz. Polycystic ovary syndrome: current status and future perspective. Front Biosci (Elite Ed) 2015; 6: 104-19.

How to cite this article : Syeda Sobia Harmain, Khan MI. Evaluation of Thyroid Function Status in Polycystic Ovary Syndrome. Perspectives in Medical Research 2020; 8(1):38-42 Sources of Support: Nil,Conflict of interest:None declared. 